\title{
MODEL PENUMBUHAN DAN PENGUATAN KELEMBAGAAN PERBENIHAN UNTUK MENINGKATKAN MUTU BAHAN TANAM DAN PRODUKTIVITAS KARET RAKYAT
}

\author{
Model of Developing and Strengthening of Rubber Nursery Institutional to Improve \\ the Quality of Planting Material and Productivity of Rubber Smallholdings
}

\author{
Lina Fatayati SYARIFA, Cicilia NANCY, dan Muhammad SUPRIADI \\ Balai Penelitian Sembawa, Pusat Penelitian Karet \\ Jalan Raya Palembang - P. Balai KM 29, PO BOX 1127 Palembang 30001
}

Diterima tgl. 20 Agustus 2011/Disetujui 14 Oktober 2011

\begin{abstract}
To support revitalization and replanting of self-help rubber plantation in Indonesia, one factor that should be considered is how to provide rubber planting material that meet the requirement of the "6 right" i.e.: right time, quantity, quality, place, clone, and price. The study aimed to analyze performance of rubber nursery institutional and to design the models of growing and strengthening of rubber nursery institutional in South Sumatra as an effort to strengthen national rubber planting material industry. This study was conducted in 2009/2010, by combining methods of survey and action research that involved participations of researchers, farmers, and other stakeholders. Selection of locations in this study was conducted purposively by selecting centre area of rubber nursery and non centre area of rubber nursery. The result showed that the budwood garden in South Sumatra Province was 236.2 ha, but until 2010 which had got certificate of Estate Agency of South Sumatra was only about $40 \%$. The dominant clones that had been cultivated were PB 260 (72.2\%), followed by IRR 39, BPM 24, and RRIC 100. The number of certified rootstocks in 2009/2010 was about 48.7 million, and about $90 \%$ of them were using seeds from Medan. In 2010, production of certified rubber planting material from South Sumatra amounted to 6.7 million. However, conditions of rubber nursery institutional in this province have not been conducive. For instances, number of supervisors and facilities provided by Seed Control and Certification Agency were still limited, many nursery operators have not got legal certificate of their product, most of nursery operators experienced limited capital, and there was limited of budwood and rootstock source. Therefore efforts should be done to improve the condition of rubber
\end{abstract}

nursery industry in South Sumatra as illustrated in the development and strengthening model as proposed.

Keyword: Hevea brasiliensis, planting material, quality, institution

\section{Abstrak}

Untuk mendukung kegiatan revitalisasi perkebunan dan peremajaan karet swadaya, maka salah satu faktor yang perlu dipertimbangkan adalah bagaimana menyediakan bibit karet yang memenuhi " 6 tepat" yaitu: tepat waktu, jumlah, mutu, tempat, klon, dan harga. Penelitian ini bertujuan untuk menganalisis keragaan kelembagaan perbenihan serta merancang model penumbuhan dan penguatan kelembagaan di Sumatera Selatan dalam upaya memperkuat industri perbenihan karet nasional. Kegiatan penelitian dilakukan pada tahun 2009/2010, dengan memadukan metode penelitian survei, dan kegiatan aksi yang melibatkan partisipasi peneliti, petani dan stakeholders lainnya. Pemilihan lokasi penelitian dilakukan secara purposive yaitu dengan memilih sentra pembibitan karet dan non sentra pembibitan karet. Hasil penelitian menunjukkan bahwa kebun entres di Provinsi Sumatera Selatan tercatat seluas 236,2 ha, namun hingga tahun 2010 yang telah mendapat SK Penetapan Dinas Perkebunan baru sekitar $40 \%$. Jenis klon yang dominan diusahakan adalah PB 260 (72,2\%), lalu IRR 39, BPM 24 dan RRIC 100. Jumlah batang bawah yang memiliki SKM (Surat Keterangan Mutu) tahun 2009/2010 di Sumsel sebesar 48,7 juta, dan sebanyak $85 \%$ menggunakan biji dari Medan. Namun, kondisi kelembagaan pembibitan karet di provinsi ini belum kondusif. Sebagai contoh, jumlah petugas 
pengawas benih serta fasilitas yang disediakan oleh Balai Pengawasan dan Sertifikasi Benih Tanaman Perkebunan masih terbatas, masih banyak penangkar pembibitan yang belum mendapat sertifikat legal bagi produk mereka, sebagian besar penangkar memiliki modal terbatas, dan sumber entres dan batang bawah juga masih terbatas. Oleh karena itu upaya yang harus dilakukan untuk memperbaiki kondisi industri karet pembibitan di Sumatera Selatan seperti yang diilustrasikan dalam model penumbuhan dan penguatan kelembagaan pembibitan karet yang diajukan dalam makalah ini.

Kata kunci: Hevea brasiliensis, bahan tanam, mutu, kelembagaan

\section{PENDAHULUAN}

Indonesia merupakan negara produsen dan pengekspor karet alam utama dunia setelah Thailand. Karet alam merupakan komoditas `strategis karena kontribusinya terhadap penerimaan devisa negara, menyerap tenaga kerja dan menjadi sumber pendapatan bagi dua juta kepala keluarga tani di pedesaan (Ditjenbun, 2009). Tanaman karet juga merupakan sumber kayu potensial dan dapat mensubstitusi kebutuhan kayu hutan yang dari tahun ke tahun ketersediaannya semakin terbatas. Indonesia memiliki areal karet terluas di antara negera-negara produsen karet alam dunia, namun produktivitasnya terendah. Penyebab rendahnya produktivitas karet Indonesia karena masih luasnya tanaman karet tua ( 100 ribu ha) yang perlu diremajakan, dan pengggunaan bahan tanaman klonal yang relatif rendah. Diperkirakan penggunaan bahan tanam karet klonal di Indonesia baru sekitar 40 $60 \%$, sementara Malaysia, Thailand, India, dan Vietnam mencapai 95-100\% (Ditjenbun, 2009).

Dalam jangka panjang, arah kebijakan pengembangan karet nasional adalah: "Agribisnis karet yang berbasis lateks dan kayu yang berdayasaing tinggi, mensejahterakan, berwawasan lingkungan dan berkelanjutan". Pada tahun 2025 diharapkan Indonesia telah menjadi negara penghasil karet alam terbesar di dunia, dengan produksi sebesar 3,5 - 4 juta ton/tahun (Ditjenbun, 2006). Sejalan dengan kebijakan di atas, Direktorat Jenderal (Ditjen) Bina Produksi Perkebunan telah menyusun Road Map Komoditas Karet Nasional guna mendukung Revitalisasi Perkebunan (Tabel 1). Sasaran jangka panjang adalah peningkatan produksi karet nasional menjadi 3,5 - 4 juta ton pada tahun 2025 dengan adopsi klon unggul menjadi lebih dari $85 \%$, sehingga produktivitas dapat ditingkatkan menjadi 1200 - 1500 kg/ha (Ditjenbun, 2005).

Untuk mencapai sasaran tersebut, maka setiap provinsi penghasil karet melakukan langkah-langkah untuk meningkatkan produksi dan produktivitasnya melalui gerakan peremajaan dan pengembangan karet. Untuk mengembangkan perkaretan nasional, sasaran pengembangan karet ditujukan pada perkebunan karet rakyat yang luasnya 85\% dari total areal perkebunan karet Indonesia dan memberikan kontribusi sekitar $81 \%$ dari total produksi karet nasional.

Untuk mendukung kegiatan peningkatan produktivitas karet rakyat, maka salah satu faktor yang perlu dipertimbangkan adalah bagaimana menyediakan bibit karet yang memenuhi " 6 tepat” yaitu: tepat waktu, jumlah, mutu, tempat, klon, dan harga. Sumatera Selatan adalah sentra pembibitan karet di Indonesia. Tulisan ini bertujuan untuk menganalisis keragaan kelembagaan perbenihan serta merancang model penumbuhan dan penguatan kelembagaan perbenihan di Sumatera Selatan.

\section{BAHAN DAN METODE}

Kegiatan penelitian dilakukan tahun 2009/2010 di Provinsi Sumatera Selatan. Penelitian ini menggunakan pendekatan penelitian partisipatif dengan menggabungkan metode penelitian survei dan penelitian aksi yang melibatkan partisipasi peneliti, petani dan stakeholder lainnya. Pemilihan lokasi penelitian dilakukan secara purposive yaitu memilih wilayah sentra pembibitan karet yaitu : Kota Lubuk Linggau, Banyuasin, Kota Prabumulih dan Kabupaten OKU Induk; dan wilayah non sentra pembibitan karet yaitu di OKI, OKU Timur dan OKU Selatan. Data yang 
dikumpulkan meliputi data primer dan data sekunder. Data primer dikumpulkan dari hasil wawancara dengan para penangkar benih dan responden terkait. Data sekunder diperoleh dari Dinas Perkebunan Provinsi dan Balai Pengawasan Sertifikasi Benih Tanaman Perkebunan (BPSBTP), dilanjutkan penelusuran data ke tingkat Kabupaten.

Kegiatan penelitian dilakukan pada 2 wilayah, yaitu di:

a. Sentra pembibitan, yaitu wilayah di mana penangkar benih karet sudah berkembang dengan jumlah produksi melebihi kebutuhan wilayah tersebut sehingga dapat dipasarkan ke luar wilayah.

b. Non sentra pembibitan, yaitu wilayah di mana sarana pembibitan belum banyak tersedia sehingga ketersediaan benih bermutu di wilayah tersebut masih sangat terbatas.

Pada wilayah sentra pembibitan, kegiatan yang dilakukan terdiri atas:

a. Pemutakhiran data penangkar, keragaan kebun entres, dan kebun pembibitan.

b. Analisis kinerja organisasi/lembaga penangkar dan implementasi perangkat peraturan perbenihan.

c. Kajian penerapan komponen model penguatan kelembagaan perbenihan yang diimplementasikan dalam kegiatan:
- Fasilitasi penguatan kapabilitas penangkar

- Fasilitasi pemurnian kebun entres

- Fasilitasi penerapan sistem Waralaba Benih

Sedangkan pada wilayah non sentra pembibitan, kegiatan yang dilakukan meliputi:

a. Pengumpulan data karakteristik dan potensi wilayah, karakteristik dan tingkat adopsi teknologi petani, dan potensi pengembangan usaha perbenihan

b. Kajian penerapan komponen model penumbuhan kelembagaan perbenihan yang diimplementasikan dalam kegiatan:

- Fasilitasi penumbuhan dan pembinaan penangkar benih

- Fasilitasi pengembangan kebun pembibitan

- Fasilitasi pemurnian kebun entres

Kemudian dilakukan kajian mengenai tataniaga bibit karet mulai dari penangkar sampai konsumen, baik konsumen perorangan maupun proyek pemerintah. Dari hasil pengumpulan data tersebut, dianalisis kelemahan, hambatan dan kendala yang dihadapi oleh para pelaku industri per-benihan yang akan dijadikan masukan untuk melakukan kajian penguatan kelembagaan perbenihan dengan menggunakan metode aksi (action research) (Babbie, 1992; Carr dan Skerritt, 1992).

Tabel 1. Road map pengembangan komoditas karet nasional

Table 1. Road map for national rubber commodities

\begin{tabular}{lccc}
\multicolumn{1}{c}{$\begin{array}{c}\text { Uraian } \\
\text { Description }\end{array}$} & \multicolumn{3}{c}{$\begin{array}{c}\text { Tahun } \\
\text { Year }\end{array}$} \\
\cline { 2 - 4 } & 2004 & $2005-2009$ & 2025 \\
\hline $\begin{array}{l}\text { Produksi (Juta ton) } \\
\text { Production (Million tons) }\end{array}$ & 1,8 & $2-2,3$ & $3-4$ \\
$\begin{array}{l}\text { Produktivitas (Kg/ha) } \\
\text { Productivity (Kg/ha) }\end{array}$ & 600 & 700 & 1200 \\
$\begin{array}{l}\text { Konsumsi domestik (\%) } \\
\text { Domestic consumption (\%) }\end{array}$ & 7 & 10 & 25 \\
$\begin{array}{l}\text { Klon unggul (\%) } \\
\text { High yielding clone (\%) }\end{array}$ & 30 & 55 & 75 \\
$\begin{array}{l}\text { Bagian petani (\% FOB) } \\
\text { Farmer Share (\% FOB) }\end{array}$ & 70 & 75 & 80 \\
$\begin{array}{l}\text { Pendapatan (US\$/KK) } \\
\text { Income (US\$/households) }\end{array}$ & 1000 & 1500 & 2000 \\
\hline
\end{tabular}

Sumber : Ditjen Bina Produksi Perkebunan (2006)

Source: Directorate General of Plantation Production Development (2006) 


\section{HASIL DAN PEMBAHASAN}

\section{Kondisi Kelembagaan Pembibitan Karet}

Di Indonesia terdapat beberapa kelembagaan yang terlibat dalam pembibitan karet, yaitu Penangkar, Asosiasi Penangkar Bibit, Balai Pengawasan dan Sertifikasi Benih Tanaman Perkebunan Tingkat Provinsi, dan Pusat Penelitian Karet.

Penangkar bibit dikategorikan berdasarkan skala usahanya terbagi dalam kelompok penangkar kecil (jumlah produksi kurang dari 5000 bibit) dan penangkar besar. Umumnya, penangkar skala besar mengusahakan bibit sendiri dalam skala luas dengan mempekerjakan masyarakat setempat, dan telah memiliki perusahaan yang berbadan hukum sehingga mereka dapat mengikuti proses tender bibit yang diadakan pemerintah maupun perusahaan swasta. Penangkar skala besar juga bisa terdiri atas beberapa kelompok yang beranggota 10 - 20 penangkar kecil yang tergabung dalam wadah koperasi. Koperasi dapat menyiapkan kebutuhan saprotan untuk anggota, kemudian mengikuti tender dan atau bekerjasama dengan suatu perusahaan untuk mencari pasar bibit dan tender, contohnya, Koperasi Sumber Rejeki yang bekerja sama dengan PT Karya Budi Sejati di Prabumulih.

Asosiasi Penangkar Bibit diperlukan untuk menghindari terjadinya persaingan yang tidak sehat di antara penangkar dalam pemasaran bibit. Asosiasi Penang-kar Bibit dibentuk pada tanggal 10 Mei 2006. Kegiatan yang sudah dilakukan antara lain menentukan standar harga jual minimal, dan mengadakan pelatihan pembibitan bagi para penangkar. Pengawasan mutu benih tersentralisasi di tingkat provinsi, karena itu pelaksanaan sertifikasi dilakukan oleh BPSBTP (Balai Pengawasan dan Sertifikasi Benih Tanaman Perkebunan). Unit Pelaksana Teknis Dinas (UPTD) perlu didukung oleh sarana/prasarana di lapangan, terutama ketersediaan tenaga teknis di lapangan (Petugas Pengawas Benih). Petugas harus diberikan pelatihan yang memadai, sehingga pada saat di lapangan memiliki kemampuan untuk melakukan seleksi, pengawasan dan pemurnian benih.
Pusat Penelitian Karet memiliki peranan utama melakukan penelitian guna mempercepat penemuan klon-klon unggul baru sehingga mempercepat pengembangan bahan tanam klon unggul baru bagi penangkar. Lembaga penelitian juga melaksanakan berbagai kegiatan antara lain pemurnian entres, pembangunan demplot pembibitan, serta berbagai kegiatan pelatihan terkait dengan masalah pembibitan maupun identifikasi klon.

\section{Kondisi dan Sebaran Kebun Entres}

Di Sumatera Selatan luas kebun entres tercatat 236,2 ha yang dibangun melalui bantuan pemerintah maupun swadaya petani (Tabel 2). Namun yang telah dimurnikan oleh Balai Penelitian Sembawa baru sekitar 75,7 ha atau $32 \%$ dari total kebun entres. Data kebun entres yang tingkat kemurniannya telah mencapai 100\% dan memperoleh SK Penunjukan Kebun Entres dari Dinas Perkebunan sekitar 86 113 batang atau 10,7 ha di tahun 2007, dan 105176 batang atau 13,1 ha di tahun 2008, sehingga total entres yang mendapat SK Disbun hingga tahun 2010 mencapai 671 ribu batang $(83,9 \mathrm{Ha})$ atau $35,5 \%$ dari total kebun entres (Tabel 2).

Kebun entres perlu mendapat SK Penetapan karena:

a) Untuk meningkatkan mutu bibit yang beredar

b) Untuk menunjukkan bahwa kebun entres telah dimurnikan

c) Untuk memenuhi legalitas hukum

Kebun entres yang memiliki SK Dinas Perkebunan Sumatera Selatan seluas 83,9 ha yang terdiri atas klon PB 260 (72,2\%), IRR $39(17,8 \%)$, BPM 24 (4,3\%), dan RRIC 100 $(2,4 \%)$ (Tabel 2).

\section{Sumber Biji Batang Bawah}

Untuk menentukan sumber biji batang bawah yang baik adalah dengan melakukan inventarisasi terhadap perkebunan karet di masing-masing wilayah karet yang dinilai layak sebagai sumber biji batang bawah, dengan persyaratan: merupakan klon anjuran batang bawah (GT 1, BPM 24, RRIC 
Tabel 2. Total kebun entres yang memiliki SK Dinas`Perkebunan Sumatera Selatan, 20072010

Table 2. Total of budwood garden which has South Sumatra Nursery Certificate, 2007-2010

\begin{tabular}{|c|c|c|c|c|c|c|}
\hline \multirow{2}{*}{$\begin{array}{l}\text { Tahun } \\
\text { Years }\end{array}$} & \multicolumn{6}{|c|}{$\begin{array}{l}\text { Klon } \\
\text { Clones }\end{array}$} \\
\hline & PB 260 & IRR 39 & BPM 24 & RRIC 100 & $\begin{array}{l}\text { Lainnya } \\
\text { Others } 1 \text { ) }\end{array}$ & Total \\
\hline 2007 & 42684 & 37599 & 1949 & 3881 & 3463 & 86113 \\
\hline 2008 & 76406 & 14613 & 8645 & 5512 & 17196 & 105176 \\
\hline $\begin{array}{c}2009 / 2010 \\
\text { Total tegakan }\end{array}$ & 365483 & 67166 & 18146 & 9804 & 19339 & 479938 \\
\hline $\begin{array}{l}\text { Total of trees } \\
\text { Total areal (ha) }\end{array}$ & 484573 & 119378 & 28740 & 19197 & 39998 & 671227 \\
\hline $\begin{array}{l}\text { Total area }(h a)^{2} \\
\text { Persentase }(\%)\end{array}$ & 60,6 & 14,9 & 3,6 & 2,4 & 5,0 & 83,9 \\
\hline Percentage (\%) & 72,2 & 17,8 & 4,3 & 2,9 & 6,0 & 100 \\
\hline
\end{tabular}

${ }^{11}$ Klon (clones) RRIM 600, IRR 118, PR 261, GT 1

2) 1 ha $=8000$ batang ( 1 ha $=8000$ trees)

Sumber: Dinas Perkebunan Sumatera Selatan, 2007-2010

Source: South Sumatra Estate Crops Office, 2007-2010

100 dan PB 260), luasan minimum 15 ha, berumur lebih dari 10 tahun, dan kondisi kebun terpelihara baik. Kebun-kebun yang memenuhi persyaratan tersebut dapat menajukan permohonan kepada Dinas Perkebunan untuk memperoleh SK penetapan sebagai sumber biji (Sesuai dengan Permentan No. 38).

Di Sumatera Selatan, ada 7 lokasi yang telah ditetapkan sebagai sumber biji batang bawah yaitu PT Pinago Utama, Balai Penelitian Sembawa, PTPN VII (UU Tebenan dan Musi Landas), PT Melania Sipef, PT Roesli Taher, dan PT Bumi Rambang Kramajaya. Pada tahun 2009/2010 biji bersertifikat (memiliki Surat Keterangan Mutu) yang ditanam penangkar di Sumatera Selatan berjumlah 48,7 juta. Apabila dikaitkan dengan ketersediaan entres bersertifikat dan tingkat keberhasilan bibit, maka potensi bibit berlabel biru hanya 14,6 juta bibit (Tabel 3). Pada tahun 2010 bibit berlabel merah tidak ada lagi, sehingga potensi bibit berlabel biru tersebut tidak mencukupi kebutuhan proyek bantuan APBD di Sumatera Selatan. Potensi bibit label biru akan bertambah apabila ada penambahan luasan entres yang memiliki SK Kebun Entres.
Dari Tabel 3 terlihat bahwa jumlah biji bersertifikat pada tahun tahun 2010/2011 menurun menjadi 37,2 juta karena berkurangnya ketersediaan biji akibat faktor cuaca. Sebagian besar penangkar di Sumatera Selatan menggunakan biji Medan (85\% di tahun $2009 / 2010$, dan $75 \%$ di tahun 2010/2011), agar dapat mengejar target bibit siap salur bulan Oktober-Nopember di tahun berikutnya.

\section{Potensi dan Produksi Bibit}

Penangkar bibit harus memiliki TRUP (Tanda Registrasi Usaha Perkebunan). Syarat memiliki TRUP adalah memiliki entres dan biji bersertifikat. Data pada Tabel 4 memperlihatkan jumlah penangkar di Sumatera Selatan yang memiliki TRUP pada tahun 2008-2010 yang menurun dari tahun ke tahun yang disebabkan antara lain:

a) Penangkar tidak memenuhi syarat untuk memiliki TRUP, karena tidak memiliki modal untuk membeli biji bersertifikat, dan memunikan kebun entres.

b) Penangkar yang tidak memiliki kelompok biasanya menjual bibit kepada petani swadaya. Namun beberapa tahun terakhir petani cenderung menunggu bantuan bibit dari Dinas Perkebunan. 
Tabel 3. Jumlah biji bersertifikat (memiliki Surat Keterangan Mutu) yang ditanam penangkar di Sumatera Selatan, 2009/2010 dan 2010/2011

Table 3. Number of certified seeds planted by nursery operator in South Sumatra, 2009/2010 and $2010 / 2011$

\begin{tabular}{|c|c|c|c|c|c|c|}
\hline \multicolumn{2}{|l|}{$\begin{array}{c}\text { Uraian } \\
\text { Description }\end{array}$} & $\begin{array}{c}\text { Satuan } \\
\text { Unit }\end{array}$ & $2009 / 2010$ & $\%$ & $2010 / 2011$ & $\%$ \\
\hline \multirow{4}{*}{$\begin{array}{l}\text { Asal Biji: } \\
\text { Seed origin: }\end{array}$} & & Butir & 41280750 & (85) & 27881000 & (75) \\
\hline & Medan & Seed & & & & \\
\hline & SumSel & Butir & 7406700 & (15) & 9403000 & (25) \\
\hline & $\begin{array}{l}\text { South Sumatra } \\
\text { Total }\end{array}$ & $\begin{array}{l}\text { Seed } \\
\text { Butir } \\
\text { Seed }\end{array}$ & 48687450 & $(100)$ & 37284000 & $(100)$ \\
\hline \multicolumn{2}{|c|}{$\begin{array}{l}\text { Potensi bibit siap salur } \\
\text { Potential of planting materials }\end{array}$} & $\begin{array}{l}\text { Polibeg } \\
\text { Polybag }\end{array}$ & 14606235 & $(30)^{*}$ & 11185200 & $(30)^{*}$ \\
\hline
\end{tabular}

* : Tingkat keberhasilan bibit: 30\% (Success rate of planting material: 30\%)

Sumber: BPSBTP (Balai Pengawasan dan Sertifikasi Benih Tanaman Perkebunan) Sumsel, 2010

Source: Seed Control and Certification Centre of Estate Crops Agency of South Sumatra, 2010

Tabel 4. Potensi bibit berdasarkan TRUP di Sumatera Selatan, 2008-2010

Table 4. Potential of planting material based on registered nursery operators in South Sumatra, 2008-2010

\begin{tabular}{|c|c|c|c|c|c|}
\hline \multirow{2}{*}{$\begin{array}{l}\text { Tahun } \\
\text { Year }\end{array}$} & \multirow{2}{*}{$\begin{array}{c}\text { Desa } \\
\text { Village }\end{array}$} & \multirow{2}{*}{$\begin{array}{c}\text { Penangkar } \\
\text { Nursery } \\
\text { Operator }\end{array}$} & \multirow{2}{*}{$\begin{array}{l}\text { Bibit } \\
\text { Planting } \\
\text { Material }\end{array}$} & \multicolumn{2}{|c|}{$\begin{array}{l}\text { Label } \\
\text { Lable }\end{array}$} \\
\hline & & & & $\begin{array}{l}\text { Biru } \\
\text { Blue }\end{array}$ & $\begin{array}{c}\text { Merah } \\
\text { Red }\end{array}$ \\
\hline 2008 & 71 & 126 & 62510330 & - & - \\
\hline 2009 & 27 & 49 & 28842241 & 18128368 & 10713873 \\
\hline 2010 & 20 & 31 & 13573492 & 13573492 & - \\
\hline
\end{tabular}

Sumber: Dinas Perkebunan Sumatera Selatan, 2010

Source: South Sumatra Estate Crops Office, 2010

Menurunnya harga karet tahun 2008/2009 menyebabkan minat menanam karet menurun, sehingga sebagian bibit karet penangkar tahun 2008 tidak terjual.

c) Bibit karet dibeli oleh pedagang skala besar yang memenangkan tender dengan harga murah.

d) Belum semua penangkar mendapat pembinaan dari Dinas Perkebunan setempat.

Berdasarkan TRUP, pada tahun 2009 potensi bibit di Sumatera Selatan mencapai 18, 1 juta untuk bibit berlabel biru (bibit yang memiliki entres dan batang bawah yang bersertifikasi) dan 10,7 juta untuk bibit berlabel merah (bibit yang memiliki entres bersertifikasi, namun batang bawah tidak bersertifikasi). Namun realisasi produksi bibit bersertifikat yang dihasilkan oleh 36 penangkar atau kelompok penangkar tahun 2009 hanya 6,4 juta batang bibit berlabel biru (35\% dari potensi bibit yang tertera pada TRUP), dan 8,5 juta batang bibit berlabel merah $(79 \%)$, dengan skala usaha mulai dari hanya 18 ribu bibit sampai hampir 5 juta bibit per penangkar. Pada tahun 2010, Pemerintah hanya memberlakukan bibit label biru. Sehingga dari potensi bibit sebesar 13,6 juta hanya tersalur 6,7 juta bibit untuk proyek pemerintah (Tabel 5). Bibit polibeg yang berasal dari penangkar Sumatera Selatan dipasok untuk Propinsi 
Tabe1 5. Jumlah bibit bersertifikat asal Sumatera Selatan berdasarkan propinsi pengguna Table 5. Number of certified planting material from South Sumatra based on consumer province

\begin{tabular}{|c|c|c|c|c|c|c|}
\hline \multirow{2}{*}{$\begin{array}{l}\text { Propinsi Pengguna } \\
\text { Consumer Province }\end{array}$} & \multicolumn{2}{|c|}{2008} & \multicolumn{2}{|c|}{2009} & \multicolumn{2}{|c|}{2010} \\
\hline & $\begin{array}{c}\text { Jumlah } \\
\text { Total }\end{array}$ & $\%$ & $\begin{array}{c}\text { Jumlah } \\
\text { Total }\end{array}$ & $\%$ & $\begin{array}{c}\text { Jumlah } \\
\text { Total }\end{array}$ & $\%$ \\
\hline Sumatera Selatan & 9340976 & 50 & 8299636 & 53 & 4900883 & 73 \\
\hline Jambi & 1207780 & 7 & 3418250 & 22 & 25000 & 0,4 \\
\hline Riau & 3454790 & 19 & 2627935 & 17 & 253693 & 4 \\
\hline Sumatera Barat & 415000 & 2 & 553680 & 4 & 518480 & 8 \\
\hline Bengkulu & 1659500 & 9 & 489950 & 3 & 152150 & 2 \\
\hline Babel & 2418316 & 13 & 297700 & 2 & 273300 & 4 \\
\hline Lampung & - & - & - & - & 585400 & 9 \\
\hline Propinsi Lain (others) & 10.000 & 0 & 58.000 & 0 & 300 & 0,004 \\
\hline Total & 18506362 & 100 & 15745151 & 100 & 6709206 & 100 \\
\hline
\end{tabular}

Sumber: BPSBTP (Balai Pengawasan dan Sertifikasi Benih Tanaman Perkebunan) Sumsel, 2010

Source: Seed Control and Certifiation Centre of Estate Crops Agency of South Sumatra, 2010

Sumatera Selatan dan luar propinsi seperti Lampung, Sumatera Barat, Riau, Bengkulu, Jambi, dan Bangka Belitung. Angka-angka ini belum termasuk bibit yang dibeli petani swadaya dan bibit tanpa label.

\section{Mutu Bibit Karet}

Meningkatnya harga karet yang cukup tinggi dewasa ini telah mengakibatkan tingginya permintaan bibit karet. Hal ini telah mendorong berkembang pesatnya usaha pembibitan karet yang dilakukan para penangkar. Namun masalah yang dijumpai di lapangan adalah mutu bibit yang dihasilkan oleh para penangkar tersebut sebagian masih rendah dan beragam, yang disebabkan oleh faktor-faktor berikut:

a) Terbatasnya jumlah dan mutu entres yang terjamin kemurniannya

b) Terbatasnya pengetahuan penangkar dan konsumen mengenai mutu bibit yang baik

c) Pengawasan mutu dan pengawalan teknis pembibitan belum dilakukan terhadap semua penangkar

d) Sebagian besar penangkar belum memiliki sertifikat dan belum menerapkan kaidah pembibitan yang baik.

Pada kenyataannya, telah banyak bibit yang diragukan mutunya dijual oleh penangkar. Dengan demikian kepentingan konsumen untuk mendapatkan bibit yang bermutu baik kurang terlindungi. Oleh karena itu UPTD - BPSBTP melakukan pembinaan terhadap penangkar dan pengawasan terhadap peredaran bibit. Sesuai dengan undang-undang No. 12 tahun 1992 bahwa bibit yang disebarkan harus bersertifikat. Di Sumatera Selatan, persyaratan untuk bibit label biru harus memiliki tingkat kemurnian entres 100\% serta memiliki entres dan biji yang bersertifikat. Apabila penangkar mendatangkan biji dari Medan, maka biji tersebut harus memiliki SKM (Surat Keterangan Mutu) biji Medan. Selanjutnya pada saat biji tiba di Palembang, biji tersebut diuji kembali sebelum BPSBTP SumSel mengeluarkan SKM yang baru. Hal ini dilakukan untuk memudahkan administrasi pada saat proses sertifikasi dan pengontrolan dari segi fisik.

\section{Sistem Tataniaga Bibit}

Kajian mengenai tataniaga bibit karet dilakukan mulai dari penangkar sampai konsumen, baik konsumen perorangan maupun proyek pemerintah. Dari Gambar 1 terlihat bahwa penangkar bibit kecil hanya mampu menyuplai bibit untuk petani swadaya yang percaya terhadap kualitas pembibitan dan tidak memerlukan bibit yang bersertifikasi. Penangkar kecil tidak dapat menyuplai bibit untuk proyek-proyek perkebunan pemerintah skala besar dikarenakan mereka tidak mampu memenuhi persyaratan sertifikasi bibit, 


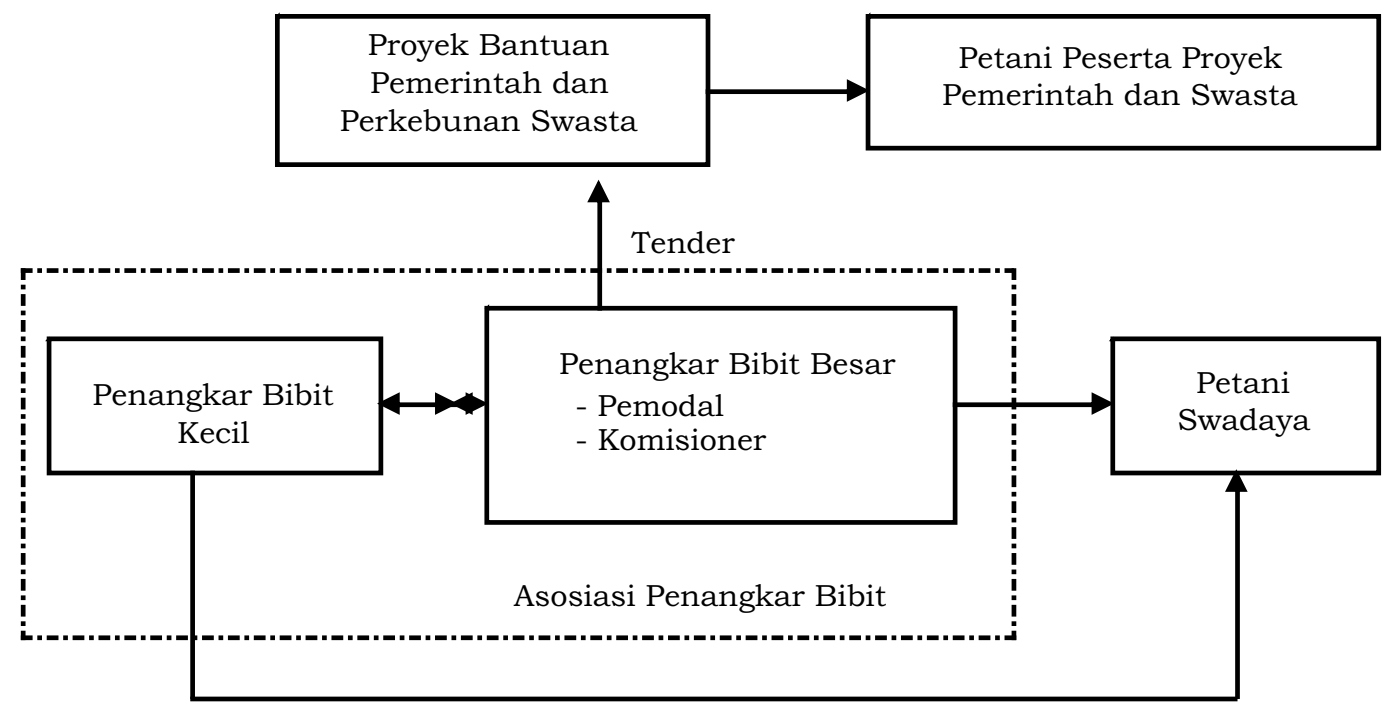

Gambar 1. Rantai pemasaran bibit karet

Figure 1. Rubber planting material marketing chain

mulai dari pengadaan biji bersertifikat sampai pemurnian kebun entres. Keberadaan Asosiasi Penangkar dibutuhkan untuk memfasilitasi para penangkar kecil dalam meningkatkan mutu bibit yang dihasilkan. Bagi penangkar kecil yang tidak memiliki mitra, maka langkah yang harus ditempuh adalah membentuk kelompok yang memiliki modal usaha untuk pembelian biji bersertifikat, pemurnian entres, dan pembuatan sertifikasi bibit.

Harga bibit karet bervariasi sesuai kondisi musim (di awal atau di akhir musim hujan). Pada tahun 2010, harga minimal bibit karet dalam polibeg di lokasi penangkar yang ditetapkan Asosiasi adalah Rp 5 500,/polibeg dan Rp. 2 500,-/stum mata tidur. Sementara harga di Balai Penelitian Sembawa mencapai Rp 6 000,- hingga Rp 6 500,-/polibeg dan Rp 3 500,- hingga Rp 4 000,-/stum mata tidur.

\section{Analisis SWOT Industri Pembibitan Karet}

Untuk mewujudkan industri perbenihan karet yang maju dan handal maka dilakukan analisis untuk mengetahui kekuatan, kelemahan, peluang serta hambaan/tantangan yang harus dihadapi industri perbenihan (Tabel 6).

\section{Model Penumbuhan dan Penguatan Kelembagaan Pembibitan}

Berdasarkan analisis SWOT yang diuraikan sebelumnya, maka dihasilkan model penumbuhan dan penguatan kelembagaan pembibitan sebagai berikut:

\section{Model penumbuhan kelembagaan pembibitan karet}

Model ini ditujukan untuk memfasilitasi pertumbuhan kelembagaan pembibitan pada daerah non sentra pembibitan. Daerah non sentra pembibitan dicirikan oleh kondisi di mana belum terdapat penangkar, sumber entres terbatas, sumber batang bawah terbatas dan harga bibit yang relatif mahal. Namun minat masyarakat untuk mengusahakan pembibitan cukup tinggi. Oleh karena itu, untuk mengembangkan industri pembibitan karet di daerah tersebut, beberapa upaya yang perlu dilakukan dapat diilustrasikan seperti yang tertera pada Gambar 2.

Fasilitasi dari berbagai institusi/ lembaga terkait seperti Pusat Penelitian Karet, Dinas Perkebunan, Balai Pengawasan dan Sertifikasi Benih Tanaman Perkebunan, Asosiasi Penangkar Benih dan Lembaga Keuangan diperlukan untuk mewujudkan 
Tabel 6. Analisis SWOT industri pembibitan karet di Provinsi Sumatera Selatan Table 6. The SWOT analysis of rubber nursery industry in South Sumatra Province

Analisis SWOT
SWOT Analysis

\section{Kelemahan}

a) Jumlah tenaga Pengawas Benih Tanaman (PBT) terbatas, demikian juga sarana yang dimiliki BPSBTP masih sangat minim.

b) Sejak tahun 2008, dalam mengikuti tender, penangkar skala besar mulai memiliki usaha berbadan hukum dan suplier bibit mulai membuat pembibitan sendiri, namun kenyataannya sebagian besar bibit mereka masih diambil dari penangkar skala kecil Terjadi persaingan yang tidak sehat antar penangkar, sehingga terjadi persaingan harga yang dimanfaatkan oleh para supplier untuk mendapat keuntungan besar dari kondisi tersebut.

c) Persyaratan sertifikasi bibit antar provinsi belum seragam .

d) Waktu kesiapan bibit tidak sesuai dengan jadwal pengadaan bibit untuk proyek, sehingga bibit belum siap salur atau bibit sudah terlalu besar (> 3 payung) sehingga tidak memenuhi persyaratan spesifikasi teknis proyek.

e) Para penangkar menghadapi keterbatasan modal, karena modal diperlukan terus menerus sampai bibit dipasarkan.

f) Para penangkar belum mengetahui dengan pasti pasar untuk bibit yang dihasilkan .

Peluang

a) Sumsel merupakan sentra pembibitan terbesar yang me nyuplai bibit ke provinsi sekitarnya.

b) Departemen Kehutanan sedang mengembangkan program Hutan Tanaman Industri Karet, yang berarti bibit karet akan diperlukan dalam jumlah besar.

c) Harga karet yang tinggi menyebabkan masyarakat akan semakin bergairah menanam karet, sehingga permintaan bibit akan terus meningkat.

\section{Hambatan/Tantangan}

a) Saat ini masih terjadi persaingan tidak sehat di antara penangkar yang mengakibatkan matinya usaha penangkar kecil .

b) Banyak bibit karet dari Sumatera Selatan dikirim ke luar provinsi secara ilegal tanpa dokumen resmi atau label.

c) Para penangkar perlu mengetahui potensi permintaan bibit setiap tahun untuk masingmasing kabupaten / kota sehingga dapat merencanakan berapa banyak bibit harus diproduksi. a) Peningkatan efektifitas kegiatan dan penguatan organisasi Asosiasi Penangkar Benih sebagai komunikasi peningkatan mutu benih karet

b) Penyebaran jenis klon baru dengan produktivitas tingg

c) Penggalakan pembuatan TRUP dan SKM

d) Sertifikasi dan labelisasi benih (biru)

e) Pengawasan peredaran dan pengujian mutu benih

f) Peningkatan pemenuhan syarat bagi peWaralaba Benih (hak dan kewajiban, aturan representasi, dan batas yurisdiksi)

a) Perekrutan tenaga baru dan pemberian pelatihan bagi calon tenaga PBT mengenai pembibitan kare

b) Peningkatan efektifitas kegiatan dan penguatan organisasi Asosiasi Penangkar Benih sebagai komunikasi peningkatan mutu benih karet

c) Penyeragaman sertifikasi bibit antar provinsi

d) Pengawalan/pendampingan teknis dan manajemen pembibitan

e) Penguatan sistem, manajemen usaha, dan modal kerja

f) Pada waktu anggaran disahkan, Dinas Perkebunan sebaiknya memberikan data kebutuhan bibit kepada penangkar sehingga dapat dipersiapkan minimal setahun sebelumnya.

a) Mempertahankan citra mutu bibit yang dihasilkan.

b) Pengawasan peredaran dan pengujian mutu benih

c) Penguatan sistem manajemen usaha pembibitan, modal kerja serta sarana dan prasarana pembibitan

a) Peningkatan efektifitas kegiatan dan penguatan organisasi Asosiasi Penangkar Benih sebaga komunikasi peningkatan mutu benih karet

b) Pengawasan peredaran dan pengujian mutu benih

c) Pemahaman terhadap kebijakan, aturan, dan perundang-undangan yang terkait dengan masalah perbenihan 


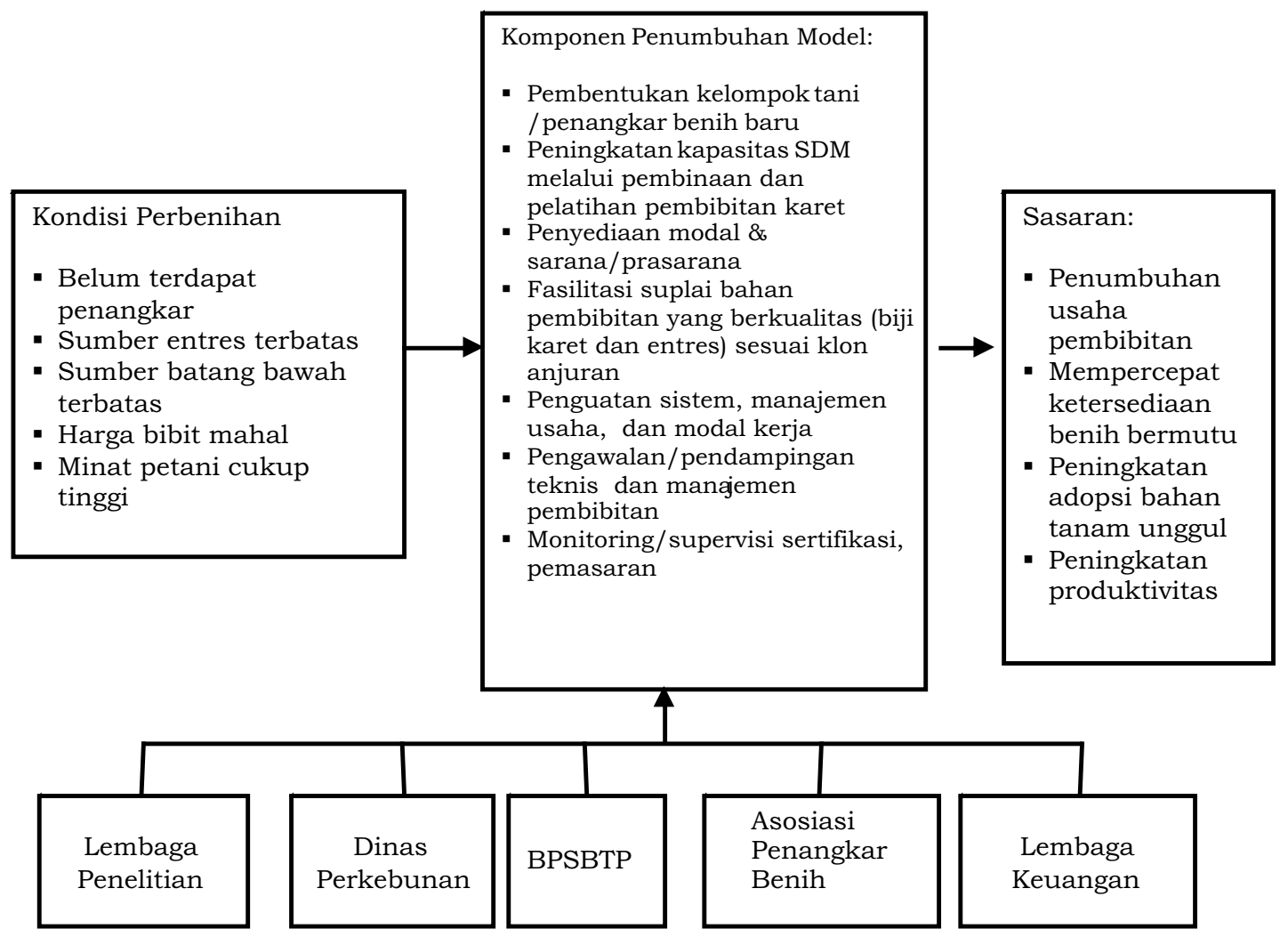

Gambar 2. Model penumbuhan kelembagaan pembibitan karet

Figure 2. Institutional growth model of rubber nursery

komponen program yang digambarkan pada model tersebut. Sementara itu, sasaran yang ingin dicapai adalah penumbuhan usaha pembibitan karet di wilayah ini, percepatan ketersediaan bahan tanam bermutu, peningkatan adopsi bahan tanam unggul dan peningkatan produktivitas perkebunan karet.

\section{Model penguatan kelembagaan pembibitan karet}

Model ini ditujukan untuk meningkatkan kinerja industri pembibitan karet di wilayah sentra pembibitan karet. Di wilayah ini telah banyak terdapat penangkar bibit karet. Namun masih terdapat berbagai permasalahan seperti mutu bibit yang beragam, bibit belum bersertifikat, entres belum dimurnikan dan sumber batang bawah tidak bersertifikat. Oleh karena itu komponen penguatan model yang dapat diterapkan seperti tertera pada Gambar 3.

\section{KESIMPULAN DAN SARAN}

Industri pembibitan karet di Sumatera Selatan telah menjadi andalan bagi penyediaan bahan tanam ke wilayahwilayah sentra karet terutama di wilayah Sumatra. Namun, kondisi kelembagaan pembibitan karet di provinsi ini belum kondusif. Sebagai contoh, jumlah petugas pengawas benih serta fasilitas yang disediakan oleh Balai Pengawasan dan Sertifikasi Benih Tanaman Perkebunan masih terbatas, masih banyak penangkar pembibitan yang belum mendapat sertifikat legal bagi produk mereka, sebagian besar penangkar memiliki modal terbatas, dan sumber entres dan batang bawah juga masih terbatas. Oleh karena itu upaya yang harus dilakukan untuk memperbaiki kondisi industri karet pembibitan di Sumatera Selatan seperti yang diilustrasikan dalam model penumbuhan dan penguatan kelembagaan pembibitan karet yang telah diajukan dalam makalah ini. 


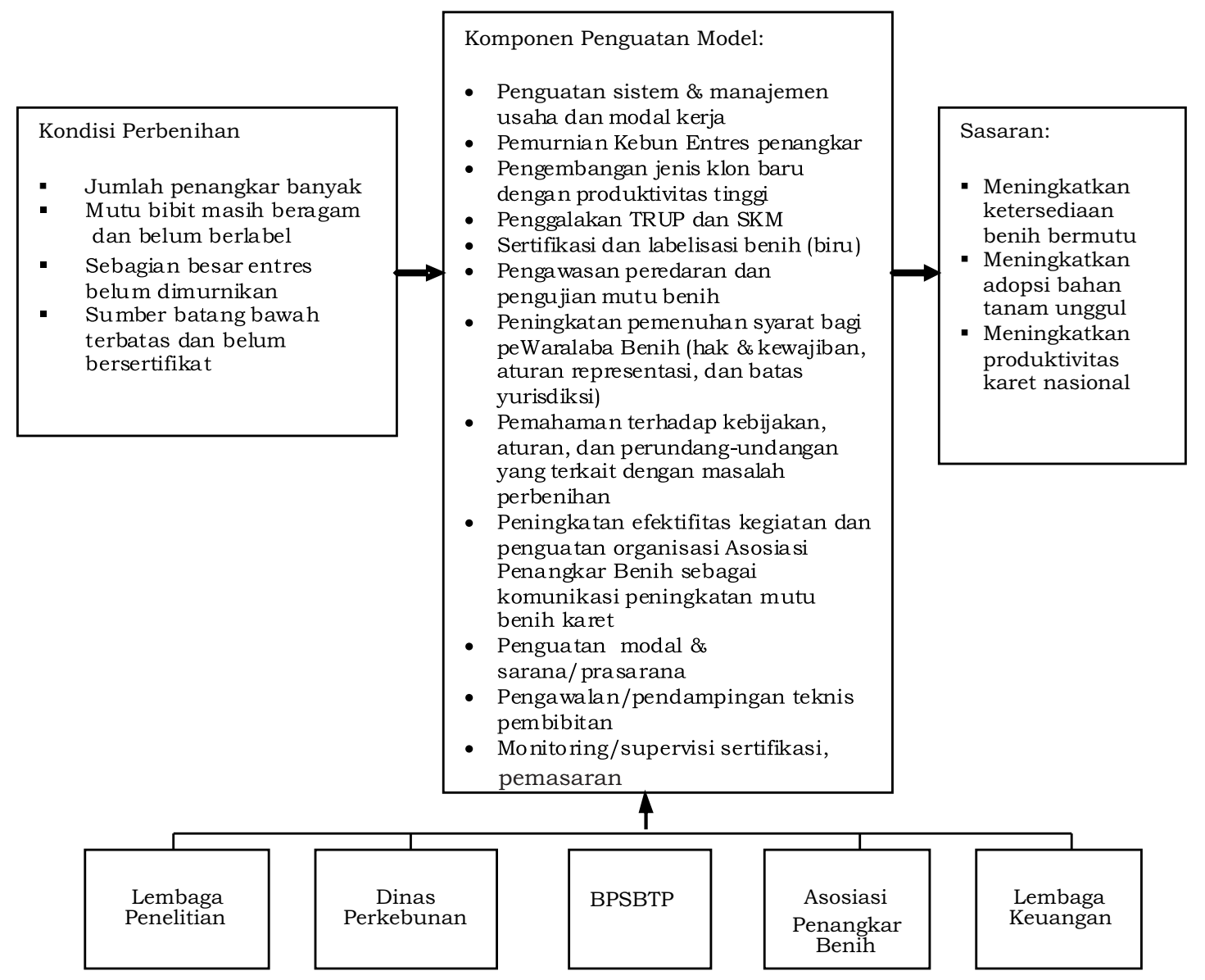

Gambar 3. Model penguatan kelembagaan pembibitan karet

Figure 3. Institutional strengthening model of rubber nursery

Selain itu, disarankan agar Asosiasi Penangkar Benih harus dapat mengakomodir penangkar pembibitan skala besar dan skala kecil. Penangkar kecil harus bisa dikelompokkan membentuk koperasi atau bergabung dengan penangkar besar yang memiliki badan usaha berbadan hukum, memiliki modal untuk pembelian biji bersertifikat, pemurnian entres dan sertifikasi bibit, sehingga kelompok tersebut dapat mengikuti tender bibit yang diadakan bagi proyek-proyek pemerintah dan swasta. Pengawasan mutu benih harus tersentralisasi di tingkat provinsi, karena itu pelaksanaan sertifikasi dilaksanakan oleh BPSBTP sebagai UPTD Dinas Perkebunan tingkat propinsi.

Balai Pengawasan dan Sertifikasi Benih Tanaman Perkebunan dan Asosiasi
Penangkar harus mensosialisasikan bibit label biru kepada para penangkar secara intensif. Selain itu, BPSBTP di tingkat provinsi perlu didukung oleh fasilitas yang memadai, terutama petugas teknis pengawasan benih tanaman. Petugas harus diberikan pelatihan teknis yang memadai, sehingga mereka memiliki kemampuan yang cukup untuk melakukan seleksi, pengawasan dan pemurnian pembibitan di lapangan. Untuk mempercepat pengembangan bahan tanam klon unggul maka Pusat Penelitian Karet harus menyediakan bahan tanam klon unggul baru untuk perluasan kebun entres bagi penangkar potensial yang difasilitasi Ditjen Perkebunan atau Dinas Perkebunan, di samping terus membantu pelaksanaan pemurnian kebun entres sebagai salah satu syarat untuk sertifikasi bibit. 


\section{DAFTAR PUSTAKA}

Babbie, E. 1992. The Practice of Social Research, 6th edn, Wadsworth Publishing Company, Belmont, California.

Carr, T and Zuber-Skerritt, O. (eds) 1992. Working Together for Quality Management: Action Research in Management and Education. The Tertiary Education Institute, Brisbane.

Direktorat Bina Produksi Perkebunan. 2006. Road Map Komoditi Karet 2005 - 2025, Ditjenbun, Jakarta.
Ditjenbun. 2005. Kebijakan nasional pengembangan karet Indonesia. Lok. Nas. Pemuliaan Tanaman Karet 2005. Pusat Penelitian Karet, Medan.

Ditjenbun. 2008. Pencapaian Program Revitalisasi Perkebunan Tahun 2008. Rapat Koordinasi Program Revitbun. Batam, 10 April 2008.

Ditjenbun. 2009. Statistik Perkebunan Karet 2008 - 2010. Departemen Pertanian. Jakarta. 